\title{
Vaginal reconstruction using a gluteal transposition flap after abdominoperineal excision for anorectal malignancy
}

\author{
Björn Bolmstrand ${ }^{1}$ (D) Pehr Sommar ${ }^{3} \cdot$ Per J. Nilsson ${ }^{1}$ - Diana Zach ${ }^{2} \cdot$ Jakob Lagergren $^{4} \cdot$ Daniel Schain $^{5}$. \\ Torbjörn Holm ${ }^{6}$. Anna Martling ${ }^{1} \cdot$ Gabriella Palmer $^{1}$
}

Received: 15 June 2021 / Accepted: 20 November 2021 / Published online: 6 February 2022

(C) The Author(s) 2022

\begin{abstract}
The purpose of this study is to present and evaluate a surgical method using gluteal flap for combined perineal and vaginal reconstruction after abdominoperineal excision (APE) with partial vaginectomy for anorectal malignancy. The method is a two-centre study of consecutive patients undergoing APE including partial vaginectomy for anorectal tumours, with immediate combined perineal and vaginal reconstruction using gluteal flaps. Follow-up data were retrieved via retrospective review of medical records, questionnaires and gynaecological examinations. Some 34 patients fulfilled the inclusion criteria. At the time of follow-up, 14 (78\%) of the 18 patients alive responded to questionnaires. Seven (50\%) of the survey responders agreed to undergo gynaecological examination. Major flap-specific complications (Clavien-Dindo > 2) were observed in 3 (9\%) patients. Among survey responders, $11(79 \%)$ had been sexually active preoperatively of which five (45\%) resumed sexual activity postoperatively and three (27\%) resumed vaginal intercourse. These three patients had all implemented an active vaginal health promotion strategy postoperatively. Perineo-vaginal reconstruction using gluteal flap after extended APE for anorectal malignancy is feasible. Although comparable to other methods of reconstruction, the rate of perineovaginal complications is high and post-operative sexual dysfunction is substantial. Postoperative strategies for vaginal health promotion may improve sexual function after vaginal reconstruction.
\end{abstract}

Keywords Rectal neoplasms $\cdot$ Anus neoplasms $\cdot$ Reconstructive surgical procedures/methods $\cdot$ Vagina/surgery $\cdot$ Surgical flaps $\cdot$ Postoperative complications

Björn Bolmstrand

bjorn.bolmstrand@sll.se

1 Dept. of Molecular Medicine and Surgery, Karolinska Institutet and Dept. of Pelvic Surgery, Unit for Coloproctology, Karolinska University Hospital, Anna Steckséns gata 30A, D2:05, 17176 Stockholm, Sweden

2 Dept. of Women's and Children's Health, Karolinska Institutet and Dept. of Obstetrics and Gynaecology, Karolinska University Hospital, Stockholm, Sweden

3 Dept. of Molecular Medicine and Surgery, Karolinska Institutet and Dept. of Reconstructive Plastic Surgery, Karolinska University Hospital, Stockholm, Sweden

4 Dept. of Molecular Medicine and Surgery, Karolinska Institutet and Dept. of Surgery, Capio S:t Görans Hospital, Stockholm, Sweden

5 Dept. of Surgery, Capio S:t Görans Hospital, Stockholm, Sweden

6 Dept. of Molecular Medicine and Surgery, Karolinska Institutet and Dept. of Surgery, South General Hospital (Södersjukhuset), Stockholm, Sweden

\section{Introduction}

Extended abdominoperineal excision (APE) including resection of the posterior vaginal wall can be necessary to obtain clear resection margins (R0) in patients with locally advanced rectal or anal cancer. As primary closure of the vaginal defect may be insufficient for anatomical restoration, flap reconstruction is used for selected patients with the aim to restore anatomy and sexual function.

Previously reported methods for perineo-vaginal reconstruction after APE are versions of the rectus abdominis myocutaneous (RAM) flap [1-3], the gracilis flap [4-6], and, to a lesser extent, different versions of gluteal flaps [7-9].

The most probable site for vaginal involvement in locally advanced anorectal cancer is the dorsal vaginal wall. Cordeiro et al. have presented a classification system and a reconstructive algorithm for acquired vaginal defects [10]. Dorsal defects are classified as type $1 \mathrm{~b}$ and the recommended flap for reconstruction is the rectus abdominis flap. Specifically, 
the vertical rectus abdominis myocutaneous (VRAM) flap is a frequently used technique [11]. The VRAM flap has the benefit of supplying bulky, well-vascularised and unirradiated tissue into the pelvic defect. Potential draw backs are added donor site morbidity with the risk of incisional hernia after harvest of one full rectus muscle. In addition, the transpelvic technique does not allow for minimal invasive surgery, presently performed in some institutions for highly selected patients requiring pelvic exenteration and potentially at a higher rate in the future $[12,13]$.

At Karolinska University Hospital where the extended or extralevator APE was pioneered, the gluteal myocutaneous flap has been the preferred method for perineal reconstruction after APE [14]. The technique previously reported has been further developed for simultaneous reconstruction of the posterior vaginal wall using an additional fasciocutaneous transposition flap.

The aim of this study is to present and evaluate this new surgical technique using gluteal flaps for reconstruction of combined perineal and posterior vaginal wall defects following extended APE for anorectal tumours.

\section{Methods}

A retrospective cohort study on consecutive female patients undergoing APE with immediate synchronous perineal and vaginal reconstruction for anorectal malignancy at Karolinska University Hospital and Ersta Hospital, Stockholm, between January 1st 2005 and December 31st 2017 was undertaken. To minimize the risk of non-inclusion of eligible patients, two registries were used for identification: (i) an in-hospital prospective database of all operative procedures and (ii) an internal patient registry. Only patients in whom both the perineal and vaginal reconstruction was performed with a gluteal flap were included.

\section{Surgical technique (Fig. 1)}

Surgical resection, including en bloc vaginal resection, and harvest of the gluteal myocutaneous flap for perineal reconstruction is performed as previously described [14]. To make vaginal reconstruction possible, an additional caudally based fasciocutaneous transposition flap is harvested adjacent to the pelvic midline defect. The flap is designed individually for each patient according to the size of the defect, e.g., $4 \mathrm{~cm}$ wide at the base and $12 \mathrm{~cm}$ in length. Sufficient mobilization achieves reach to the posterior vaginal wall. Perforator vessels are not visualized and the base of the flap is left as a bulk of fatty tissue securing sufficient blood supply from random circulation of the inferior gluteal and pudendal vessels. After mobilization, the fasciocutaneous transposition flap is rotated 180 degrees along a cranio-caudal axis into the midline defect which allows for the gluteal skin to be used for reconstruction of the dorsal vaginal wall. When necessary, the flap is trimmed cranially to fit the defect. Using a single layer of interrupted resorbable sutures, the flap is sutured to the cut edges of the vagina. For patients in whom the most distal part of vagina is not resected and the introitus remains intact, the caudal part of the transposition flap can be deepithelialized to allow the gluteal skin in the cranial part of the flap to reach the defect in the posterior vaginal wall.

Subsequently, the cranially based myocutaneous gluteal flap is rotated over the midline defect and sutured to the opposite side gluteal muscle. Postoperatively, the patient is kept on a decubital mattress and mobilized according to a specific schedule [14].

All reconstructive surgery for patients included in this report was performed by board-certified plastic surgeons.

\section{Data collection}

For patients included, all available in- and out-patient medical records were searched for data. Data collected included age, diagnosis, ASA score, neoadjuvant treatment, date and type of surgery, operative time (specified as time for resection and reconstruction), intensive care unit admissions, reoperations, interventional radiology procedures, postoperative treatment with antibiotics, length of hospital stay and vital status including date of death. Any complication detected within 30 days postoperatively was recorded and graded according to the Clavien-Dindo classification system of surgical complications [15]. In addition, complications related specifically to the perineo-vaginal reconstruction were recorded separately and sub-grouped into early and late complications. Early complications were defined as occurring within 30 days postoperatively and late complications when detected thereafter or persisting 90 days postoperatively.

Questionnaires were used to evaluate quality of life (QoL) and sexual function among patients alive at follow-up. For evaluation of QoL, the European Organization for Research and Treatment of Cancer general Quality of Life Questionnaire (EORTC QLQ-C30) was used. In absence of an anal cancer-specific survey, the EORTC QLQ-CR 29 (colorectal module) questionnaire was used to assess disease specific issues for all patients [16]. The Female Sexual Function Index (FSFI) was used to assess sexual function. The FSFI is a 19-item self-report survey that provides scores on overall levels of sexual function that has been validated in cancer survivors [17, 18]. A 5-point Likert scale generating an overall score is used to assess domains of female sexual function including desire, arousal, lubrication, orgasm, satisfaction, and pain. Overall score ranges from 2 to 36 and a higher score indicates a higher sexual function. A cut-off value of below 


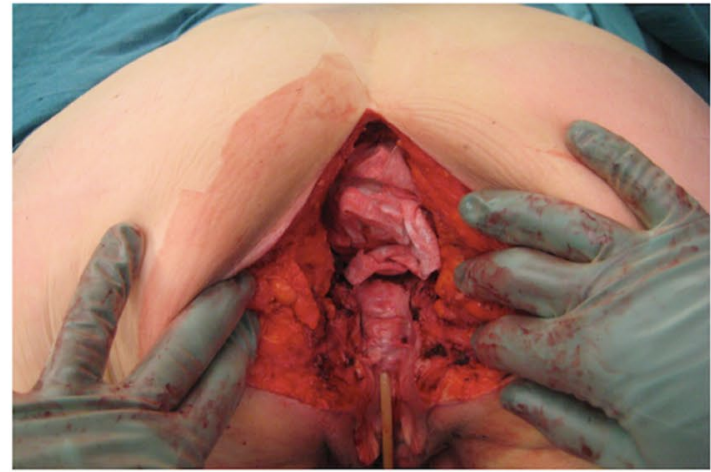

a In prone position after APE with excision of the dorsal vaginal wall.

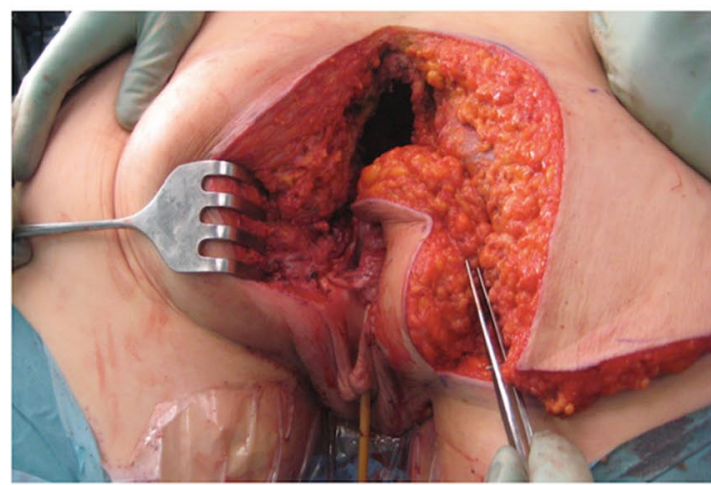

c After incision.

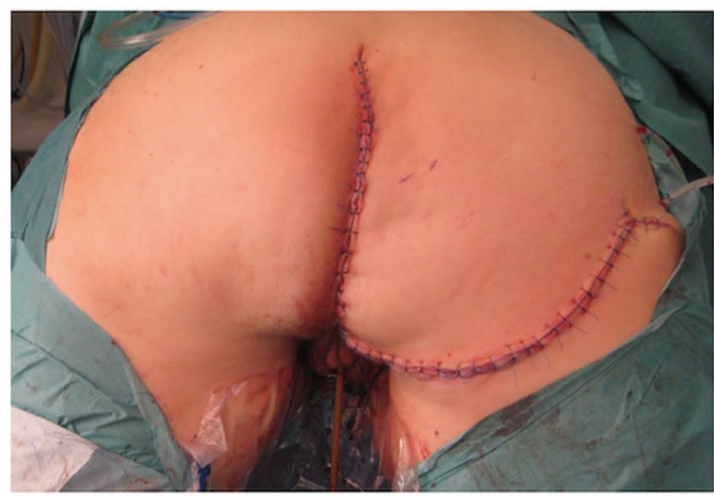

e After rotation of the myocutaneous flap for perineal reconstruction.

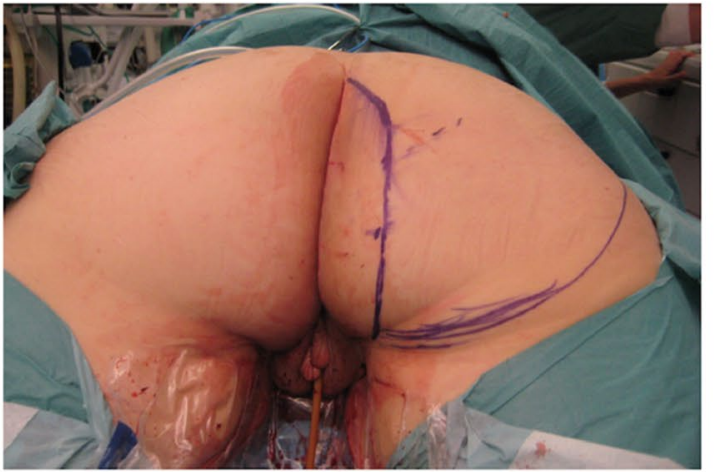

b Outline of the incision-lines for gluteal flap.

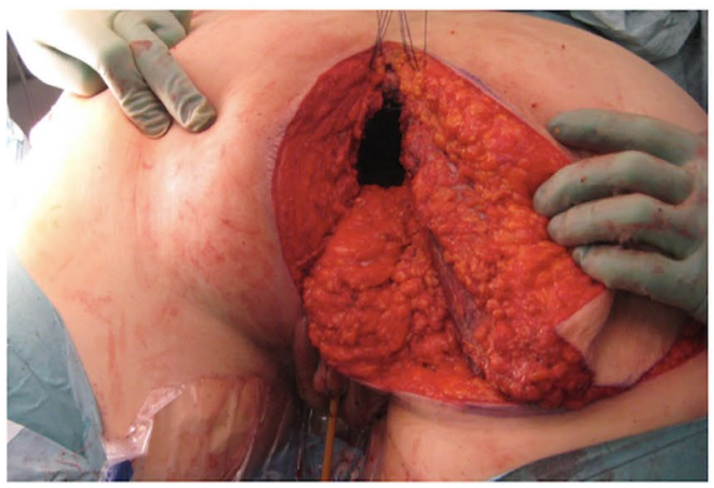

d After transposition of the caudally based fasciocutaneous flap for dorsal vaginal wall reconstruction.

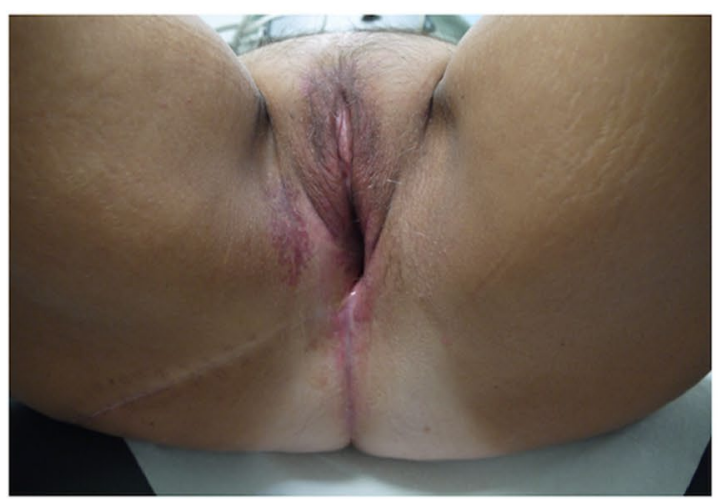

f One year postoperatively.

Fig. 1 Surgical technique for immediate synchronous perineo-vaginal reconstruction using gluteal flap after APE ${ }^{\mathrm{a}}$ for anorectal malignancy

26.55 has previously been validated as indicating female sexual dysfunction [17]. As valid interpretation of the FSFI requires sexual activity within the last 4 weeks, additional set of questions were administered to assess preoperative versus post-operative sexual activity and reasons for any sexual inactivity (Appendix Table A8). Additionally, menopausal status at time of operation and whether the reconstructive surgery had been succeeded by any active strategy for vaginal health 
promotion was recorded in an interview setting, either in conjunction with a gynaecological examination or, for those who declined the examination, over the phone. Active vaginal health promotion was defined as systematic use of dilators, vaginal moisturizers and lubricants, pelvic floor exercises and local or systemic hormone replacement therapy (Appendix Table A9). Systemic hormone replacement alone was not considered active vaginal health promotion.

All questionnaire responders were invited to undergo a gynaecological examination that was conducted according to a pre-specified check-list (Appendix Table A10). During the examination, neovaginal elasticity, wall thickness, epithelial integrity and vascularity for both the residual vagina and the flap were recorded. In addition, neovaginal $\mathrm{pH}$ level, length and diameter were measured and any presence of stenosis or hair growth noted. The check-list for the gynaecological examination and the set of questions regarding vaginal health promotion were both based on versions developed and validated within The Female Sexual Medicine and Women's Health Program at Memorial Sloan Kettering Cancer Center [19].

\section{Ethical approval}

Ethical approval for the study was granted by the regional ethics committee of Stockholm (Regional Ethical Vetting Board, Stockholm, Sweden, Dr 2015/1547-31/4).

\section{Statistical analysis}

Study data were analysed using the statistical software program STATA ${ }^{\circledR}$ version 14.0 (StataCorp LP, College Station, TX, USA). Groups were compared with Fisher's exact test and $p$ values $<0.05$ were considered statistically significant.

\section{Results}

In total, 34 patients fulfilled the inclusion criteria during the study period. At the time of follow-up, 16 patients (47\%) were deceased, one (3\%) suffered from severe dementia and three $(9 \%)$ did not respond to any attempts of contact. The remaining 14 patients (41\%) all responded to questionnaires and seven of these patients (21\%) agreed to further participation through gynaecological examination (Fig. 2.) Median follow-up time in the study was 622,5 days (8-3830+).

Patient characteristics, preoperative treatment and surgical details are presented in Table 1. All patients received pelvic external beam radiotherapy (RT) preoperatively. Among the 20 patients (59\%) treated for primary rectal cancer, 13 (38\%) received conventional long-course (1.8-2 Gy $\times 25-28)$ chemoradiotherapy (CRT). The remaining seven patients $(21 \%)$ received short-course RT $(5 \mathrm{~Gy} \times 5)$ of whom four $(12 \%)$ in combination with preoperative chemotherapy. The two patients $(6 \%)$ with locally recurrent rectal cancer were initially treated with long-course $\mathrm{RT}$, no re-irradiation was administered prior to surgery for the recurrent tumours. Among the 11 patients (32\%) with residual or recurrent anal cancer, seven were treated with conventionally fractionated concurrent $\mathrm{CRT}$ in doses ranging from 46 to $60 \mathrm{~Gy}$. The remaining four patients were treated with RT alone prior to salvage surgery. The single patient with a re-recurrence of anal cancer was treated with irradiation alone prior to salvage surgery and was administered chemotherapy but no re-irradiation prior to surgery for the re-recurrence.

\section{Surgical details}

From chart review, it is evident that 31 patients $(91 \%)$ underwent extralevator APE, whereas precise surgical details for three patients (9\%) were lacking. All patients underwent vaginal resection. Additional operative details are presented in Table 2. All patients underwent surgery with curative intent and histopathology reports showed that clear margins (R0) was achieved in 31 patients $(91 \%)$.

The vaginal resection included introitus in 26 patients (76\%) leaving eight patients (26\%) with an intact introitus. Perineal reconstruction was performed using a unilateral gluteal flap in all but one patient. For the remaining patient perineal reconstruction was performed using bilateral gluteal flaps. For vaginal reconstruction the fasciocutaneous rotational flap described above was performed in all patients. Perineo-vaginal reconstruction added a median of $139 \mathrm{~min}$ (69-198) to the operative time.

\section{Complications as revealed by review of medical records}

Major complications (Clavien-Dindo $>2$ ) including one post-operative death on day 8 , occurred in nine patients (26\%) (Table 3). Early complications related specifically to the perineo-vaginal reconstruction were seen in 15 patients (44\%). In Table 4, details on early and late perineo-vaginal complications are presented. Only one partial flap loss was observed and necessitated a re-operation (Clavien-Dindo IIIb). The most common complication was perineal infection or dehiscence which was experienced by 13 patients (38\%) with or without an underlying pelvic abscess. Two patients developed a pelvic abscess without signs of wound infection. Late perineo-vaginal complications were detected in 11 patients (32\%). Among the 15 patients with early perineo-vaginal complications, eight (24\%) went on to have complications at 90 days. Late complications included three patients with cutaneo-vaginal fistulas that were managed conservatively and one patient with an underlying chronic pelvic abscess who developed an entero-vaginal fistula that required re-operation. 
Fig. 2 Flowchart

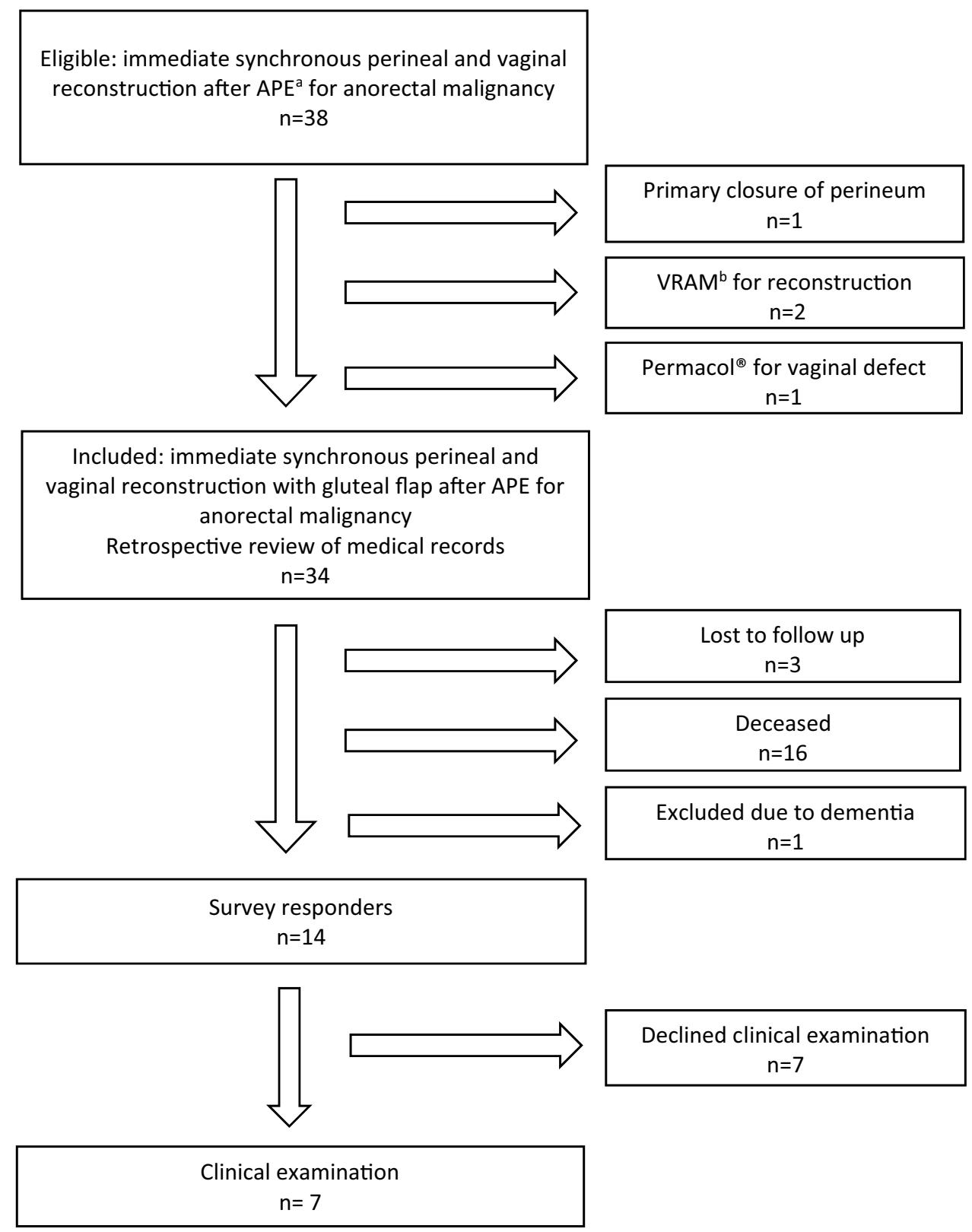

The perineo-vaginal complication rates for patients treated for anal and rectal cancer were $58 \%$ and $50 \%$, respectively $(p=0,73)$.

\section{Gynaecological examination}

Seven patients underwent the per protocol gynaecological examination of which five (71\%) were assessed as having anatomically favourable results. In the remaining two patients (29\%), partial neovaginal stenosis was observed. Median neovaginal length was $75 \mathrm{~mm}$ (range: 50-90 mm) and median neovaginal diameter (largest dilator not causing discomfort) was $27.5 \mathrm{~mm}$ (range: $20-35 \mathrm{~mm}$ ). In all but one patient, the neovagina was assessed to have excellent to fair elasticity and no differences were observed between the residual vagina and the flap in regards to wall thickness, epithelial integrity or vascularity. Additional late complications detected at gynaecological examination were hair growth on the vaginal flap $(n=3)$ and cystocele $(n=1)$.

\section{Postoperative sexual function, neovaginal health promotion and QoL}

Among the 14 questionnaire responders, seven had a current partner and $11(79 \%)$ described themselves as sexually active pre-therapeutically (Table 5). Among the sexually active, five (45\%) resumed some form of sexual activity post-treatment and three patients $(27 \%)$ reported preserved capacity for vaginal intercourse. The 14 responders included nine rectal and five anal cancer patients. For rectal and anal 
Table 1 Baseline characteristics of patients undergoing synchronous primary perineo-vaginal reconstruction with a gluteal flap after $\mathrm{APE}^{\mathrm{a}}$ for anorectal malignancy, $n=34$

\begin{tabular}{ll}
\hline Variable & $*$ \\
\hline Age (years), median (range) & $60(33-83)$ \\
BMI, median (range) & $23(19-49)$ \\
ASA score & $21(62 \%)$ \\
$1-2$ & $13(38 \%)$ \\
$3-4$ & \\
Origin and presentation of cancer & \\
Rectal & $20(59 \%)$ \\
$\quad$ Primary & $2(6 \%)$ \\
$\quad$ Recurrent & $8(24 \%)$ \\
Anal & $3(9 \%)$ \\
Residual & $1(3 \%)$ \\
$\quad$ Recurrent & \\
Re-recurrent & $3(9 \%)$ \\
Neoadjuvant treatment & $4(12 \%)$ \\
Short course radiotherapy alone & $5(15 \%)$ \\
Short course radiotherapy w. chemotherapy & $22(65 \%)$ \\
Long course radiotherapy alone & \\
Chemoradiotherapy & \\
\hline abdominoperineal excision & \\
* Digits represent numbers of patients (\%) if not specified otherwise
\end{tabular}

cancer patients, pre-treatment sexual activity ( 8 vs. 3 ), posttreatment sexual activity ( 3 vs. 2 ), and preserved capacity for vaginal intercourse (2 vs. 1) were reported, respectively.

Among the five patients who reported resumed sexual activity post-treatment, three were sexually active at time of participation in the study. Two of these three patients scored below 26.5 points according to the FSFI, indicating sexual dysfunction. Three patients reported post-treatment sexual activity including vaginal intercourse and they had all implemented an active strategy for vaginal health promotion postoperatively. In total, less than one-third of the questionnaire responders had implemented such a strategy. Among the ten patients who had not implemented such a strategy, at least five could not recall any information in regards to vaginal health promotion.

Scale scores of the Quality of Life questionnaires are presented in Table 6 (EORTC QLQ-C30) and Table 7 (EORTC QLQ-CR29). The results indicate a substantial impairment in quality of life regarding global health status, anxiety and body image, while remaining functional scales are less affected.

\section{Discussion}

This report presents a novel technique for vaginal reconstruction using a gluteal fasciocutaneous transposition flap. Performed as a supplement to the gluteus maximus rotational
Table 2 Surgical details in patients undergoing synchronous primary perineo-vaginal reconstruction with a gluteal flap after $\mathrm{APE}^{\mathrm{a}}$ for anorectal malignancy, $n=34$

Resection beyond the $\mathrm{TME}^{\mathrm{b}}$ planes

\begin{tabular}{ll}
\hline Hysterectomy & $24(71 \%)$ \\
Salpingoofrectomy, unilateral & $1(3 \%)$ \\
Salpingoofrectomy, bilateral & $22(65 \%)$ \\
Sacrectomy (level S3) & $1(3 \%)$ \\
Extended lateral pelvic sidewall resection & $1(3 \%)$ \\
Lateral lymph node dissection & $4(12 \%)$ \\
Nephrectomy & $1(3 \%)$ \\
Partial resection of ureter & $1(3 \%)$ \\
Operative time & \\
Total, minutes, median (range) & $541(376-802)$ \\
Perineo-vaginal reconstruction, minutes, median & $139(69-198)$ \\
(range) & \\
R0 resection & \\
Rectal cancer & $20(100 \%)$ \\
Primary $(n=20)$ & $2(100 \%)$ \\
Recurrent $(n=2)$ & \\
Anal cancer & $7(88 \%)$ \\
Residual $(n=8)$ & $2(67 \%)$ \\
Recurrent $(n=3)$ & $0(0 \%)$ \\
Re-recurrent $(n=1)$ &
\end{tabular}

*Digits represent numbers of patients (\%) if not specified otherwise

${ }^{\mathrm{a}}$ Abdominoperineal excision

${ }^{\mathrm{b}}$ Total mesorectal excision

Table 3 Complications according to Clavien-Dindo within 30 days postoperatively

\begin{tabular}{lll}
\hline Clavien-Dindo score & Total* & $\begin{array}{l}\text { Perineo-vaginal } \\
\text { reconstruction* }\end{array}$ \\
\hline 0 & $10(29 \%)$ & $19(56 \%)$ \\
I & $1(3 \%)$ & $1(3 \%)$ \\
II & $14(41 \%)$ & $11(32 \%)$ \\
IIIa & $3(9 \%)$ & $2(6 \%)$ \\
IIIb & $2(6 \%)$ & $1(3 \%)$ \\
IVa & $2(6 \%)$ & - \\
IVb & $1(3 \%)$ & - \\
V & $1(3 \%)$ & - \\
\hline
\end{tabular}

*Digits represent numbers of patients (\%)

flap, it allows for restoration of the pelvic floor and a chance to preserve sexual function after extended abdominoperineal excision with partial vaginectomy for anorectal malignancy.

In the current cohort of 34 patients, the procedure appears feasible with only one partial flap loss, an acceptable overall complication rate and reported return to sexual activity including vaginal intercourse in some patients. However, 
Table 4 Complications associated with the perineovaginal reconstruction as revealed by review of medical records $(n=34)$

\begin{tabular}{llll}
\hline $\begin{array}{l}\text { Early complications } \\
\text { (30 days) }\end{array}$ & $\begin{array}{l}\text { Number } \\
(\%)\end{array}$ & $\begin{array}{l}\text { Late complications } \\
\text { (Post 90 days) }\end{array}$ & $\begin{array}{l}\text { Number } \\
(\%)\end{array}$ \\
\hline $\begin{array}{l}\text { Wound infection/dehiscence } \\
\text {-Perineal }\end{array}$ & $7(21 \%)$ & Wound infection/dehiscence \\
-Vaginal & $4(12 \%)$ & -Perineal & $2(6 \%)$ \\
-Combined & $2(6 \%)$ & -Vaginal & $1(3 \%)$ \\
Partial flap loss & & -Combined & $1(3 \%)$ \\
-Perineal & $1(3 \%)$ & Fistulas & $1(3 \%)$ \\
-Vaginal & $0(0 \%)$ & -Entero-vaginal & $3(9 \%)$ \\
Pelvic abscess & $6(18 \%)$ & -Cutaneo-vaginal & $1(3 \%)$ \\
& & Chronic pelvic abscess & $1(3 \%)$ \\
& & Vaginal synechiae & $1(3 \%)$ \\
& & Enterocele & $1(3 \%)$ \\
\hline
\end{tabular}

Table 5 Details on sexual function, vaginal health promotion strategies and menopausal status for survey responders, $n=14$

\begin{tabular}{ll}
\hline Variable & Number $(\%)$ \\
\hline Sexually active pre-treatment & \\
-Yes & $11(79 \%)$ \\
-No & $3(9 \%)$ \\
Sexually active post-treatment & \\
-Yes & $5(36 \%)$ \\
-No & $9(64 \%)$ \\
Vaginal intercourse post-treatment $(n=13)$ & \\
-Yes & $3(23 \%)$ \\
-No & $7(54 \%)$ \\
-Do not know & $3(23 \%)$ \\
Treatment have changed sexual enjoyment $(n=13)$ & \\
-Yes & $9(69 \%)$ \\
-No & $0(0)$ \\
-Do not know & $4(31 \%)$ \\
Menopausal status at time of treatment & \\
-Pre & $3(21 \%)$ \\
-Peri & $2(14 \%)$ \\
-Post & $9(64 \%)$ \\
Active implementation of vaginal health promotion & \\
strategy post-treatment & \\
-Yes & \\
-No & $3(21 \%)$ \\
Reasons stated for no implementation $(n=10)$ & $4(43 \%)$ \\
-No information & $10(71 \%)$ \\
-Age & \\
-No reason stated & $5(50 \%)$ \\
Vaginal health promotion strategy post-treatment & $1(10 \%)$ \\
-Dilator therapy & $4(40 \%)$ \\
-Vaginal lubricant with sexual activity & \\
-Pelvic floor exercise & \\
-Local hormonal therapy & \\
\hline
\end{tabular}

Table 6 EORTC QLQ-C30 in patients after perineo-vaginal reconstruction with gluteal flaps after APE for anorectal malignancy, $n=14$

\begin{tabular}{lll}
\hline Overall $^{\mathrm{a}}$ & Mean score & (range) \\
\hline $\begin{array}{l}\text { Global health status } \\
\text { Function }\end{array}$ & 50 & $(0-92)$ \\
Physical & 70 & \\
Role & 71 & $(25-100)$ \\
Emotional & 72 & $(25-100)$ \\
Cognitive & 80 & $(31-100)$ \\
Social & 71 & $(38-100)$ \\
Symptoms & & $(25-100)$ \\
Fatigue & & \\
Nausea and vomiting & 45 & $(0-100)$ \\
Pain & 10 & $(0-100)$ \\
Dyspnoea & 54 & $(0-100)$ \\
Insomnia & 33 & $(0-100)$ \\
Appetite loss & 36 & $(0-100)$ \\
Constipation & 12 & $(0-67)$ \\
Diarrhoea & 14 & $(0-100)$ \\
Financial difficulties & 14 & $(0-67)$ \\
\hline
\end{tabular}

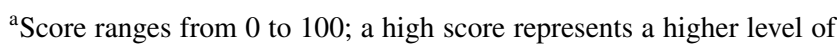
function

${ }^{\mathrm{b}}$ Score ranges from 0 to 100 ; a high score represents more severe symptoms

overall perineo-vaginal wound morbidity was substantial, amounting to over $50 \%$. Perceived advantages of the described surgical method include favourable cosmesis as the incision line in the gluteal fold preserves the natural form of the buttock and the base of the transposition flap recreates a distinct transition between the perineum and the vaginal cavity. In common with the gluteus maximus rotational flap, it is easy to harvest and does not rely on pedicelled circulation.

The advancement of irradiated tissue into the perineal defect must be considered a disadvantage of this procedure. However, when comparing complication rates with those 
Table 7 EORTC QLQ-CR29 in patients after perineo-vaginal reconstruction with gluteal flap after APE for anorectal malignancy, $n=14$

\begin{tabular}{lll}
\hline Function $^{\mathrm{a}}$ & Mean score & $($ range $)$ \\
\hline Anxiety & 50 & $(0-100)$ \\
Body image & 37 & $(0-100)$ \\
Sexual function $(n=13)$ & 90 & $(67-100)$ \\
Symptoms & & \\
Micturition problems & 37 & $(0-67)$ \\
Abdominal and pelvic pain & 28 & $(0-78)$ \\
Defecation problems & 9 & $(0-33)$ \\
Fecal Incontinence & 36 & $(0-83)$ \\
Bloated feeling & 31 & $(0-100)$ \\
Dry mouth & 33 & $(0-100)$ \\
Hair loss & 0 & $(0)$ \\
Trouble w. taste & 7 & $(0-33)$ \\
Sore skin & 24 & $(0-100)$ \\
Embarrassed by bowel movement & 60 & $(0-100)$ \\
Stoma-related problems & 17 & $(0-67)$ \\
Dyspareunia $(n=5)$ & 40 & $(0-67)$ \\
\hline
\end{tabular}

${ }^{a}$ Score ranges from 0 to 100 ; a high score represents a higher level of function

${ }^{\mathrm{b}}$ Score ranges from 0 to 100 ; a high score represents more severe symptoms

after vertical rectus abdominis myocutaneous (VRAM) flap, the difference is limited. In a study of 69 patients reconstructed with VRAM after APE for locally advanced rectal cancer, of which 47 patients were operated with combined perineo-vaginal reconstruction, the observed perineal complication rate was $36 \%$, not including pelvic abscess formation reported in $10 \%$ of patients [20]. Other studies on VRAM in similar settings have reported perineal complication rates ranging between 46 and 50\% [21, 22]. Pelvic abscess formation was more common in the current study, $18 \%$ compared to $0-10 \%$, as reported following VRAM reconstruction [20-22]. This may, in addition to advancement of irradiated tissue, be attributed the inferior filling of the dead space within the pelvis when a gluteal flap is used compared to VRAM. It is possible that an omentoplasty, in conjunction with gluteal flap reconstruction, could mitigate these problems, but evidence is lacking [23]. Perineal herniation has been reported more frequent after gluteal flap reconstruction compared to after VRAM [24]. No perineal hernias were observed in this study.

Although sample size is limited, one can observe that perineo-vaginal complications appear to occur more often among anal cancer patients compared to those with rectal cancer. It is possible that both irradiation techniques (volume and dose) and surgical technique may increase the risk of complication for anal cancer patients [25].

The most recent systematic review indicates that restoration of sexual function after APE with partial vaginectomy for colorectal malignancy is difficult with a pooled success rate of 50\% [26]. Our results point in the same direction. A separate study on sexual dysfunction after perineo-vaginal reconstruction with VRAM reports a $14 \%$ rate of return to sexual activity [27]. However, all reporting on this topic is complicated by the fact that there up until recently has been no standardized, validated method for investigating return of sexual function after extensive pelvic surgery. FSFI is validated in cancer survivors but not intended as a tool to explore reasons for sexual inactivity [17, 28, 29]. A recent study from Denmark has introduced "The Rectal Cancer Female Sexuality Score". It has been validated among Danish women treated for rectal cancer and may prove a useful tool in the future, but was unfortunately not made available until after the current study was conceived [30].

In the literature on vaginal reconstruction, references to post-operative strategies for vaginal health promotion are almost non-existing. In a study of patients with a history of breast, gynaecological or colorectal/anal cancer, significant improvement of sexual function was observed after implementation of easy-access treatment strategies including vaginal moisturizers, vaginal lubricants, pelvic floor exercises and dilator therapy. Additional findings were improvement of vulvovaginal symptoms and less pain associated to gynaecological examinations [19]. Thus, it appears that vaginal health promotion strategies are important for cancer survivors and it may be hypothesised to be even more important following reconstruction of the vagina per se. Our finding that all three patients who resumed vaginal intercourse had implemented such a strategy is noteworthy and indicates that a formalized post-operative counselling package regarding such strategies should be implemented for all patients undergoing vaginal reconstruction. Although one cannot state that there is high-grade evidence to do so, it is highly unlikely that such a strategy would be harmful to any patient.

The current study has several limitations. Data were collected retrospectively and all relevant information may not be available in patient records and operative notes. This report is based on a series of patients where a uniform technique was applied, but no comparators are available. Despite being one of the largest cohorts to date of any one specific method for vaginal reconstruction after APE, the sample size is still small and the cohort heterogeneous regarding diagnosis, neoadjuvant treatment and time to follow-up. This makes interpretation of results difficult.

\section{Conclusion}

Perineo-vaginal reconstruction using gluteal flap after extended APE for anorectal tumours is feasible. However, the rate of perineo-vaginal complications is high and postoperative sexual dysfunction substantial. Postoperative 
strategies for vaginal health promotion may improve sexual function after vaginal reconstruction.

\section{Appendix 1}

See Appendix Tables 8, 9, 10
Table 8 Additional set of questions to assess preoperative vs. postoperative sexual activity and reasons for any sexual inactivity
Patient nr: Instructions:

The following questions regard sexuality. Your answers will be kept strictly confidential. When answering the questions, the following definitions apply:

Sexual activity: touching, foreplay, masturbation or vaginal intercourse

Vaginal intercourse: penetration of the vagina

1. Were you sexually active before the cancer treatment?
$\square$ Yes
No

2. Have you been sexually active after the operation?

$\square$ Yes $\quad \square$ No $\square$ Have tried but discontinued

3. Have you been able to engage in vaginal intercourse after the operation?
$\square$ Yes
No $\square$ Do not know
$\square$ Have tried but discontinued

4. Has the pleasure you experience when engaged in sexual activity changed after the operation?
$\square$ Yes
No $\square$ Do not know

5. If you answered "No" or "have tried but discontinued" please tick the box in front of the explanation that best describes why

$\square$ pain

$\square$ no desire

$\square$ worried it will hurt

$\square$ worried it will be dangerous

the vagina is too small

other reason (please describe in your own words): 
Table 9 Check-list for questions regarding vaginal health promotion strategies
Vaginal health promotion strategies ${ }^{\mathrm{a}}$

(Please check appropriate response)

\begin{tabular}{|c|c|c|c|c|}
\hline \multicolumn{5}{|c|}{ Pelvic floor exercises } \\
\hline Never & Rarely & A few times/w & Daily & Not applicable \\
\hline \multicolumn{5}{|c|}{ Dilator therapy } \\
\hline Never & Rarely & A few times/w & Daily & Not applicable \\
\hline \multicolumn{5}{|c|}{ Vaginal lubricants } \\
\hline Never & Rarely & A few times/w & Daily & Not applicable \\
\hline \multicolumn{5}{|c|}{ Vaginal lubricants with sexual activity } \\
\hline Never & Rarely & Sometimes & Always & Not active \\
\hline \multicolumn{5}{|c|}{ Local estrogen treatment } \\
\hline yes & no & & & \\
\hline \multicolumn{5}{|c|}{ Systemic estrogen treatment } \\
\hline yes & no & & & \\
\hline \multicolumn{5}{|c|}{ Reason for no implementation: } \\
\hline \multicolumn{5}{|c|}{ Menopausal status at time of operation } \\
\hline \multicolumn{5}{|c|}{ Pre } \\
\hline \multicolumn{5}{|l|}{ Peri } \\
\hline Post & & & & \\
\hline
\end{tabular}

${ }^{a}$ Modified version of check-list developed and validated within The Female Sexual Medicine and Women's Health Program at Memorial Sloan Kettering Cancer Center

Table 10 Neovaginal examination check-list

\begin{tabular}{|c|c|c|c|c|}
\hline \multicolumn{5}{|c|}{ Neovaginal examination check-list ${ }^{\mathrm{a}}$} \\
\hline $\mathrm{pH}$ & $<5$ & $>5$ & & Not assessed \\
\hline $\begin{array}{l}\text { Elasticity } \\
\text { Flap }\end{array}$ & $\begin{array}{l}\text { Excellent } \\
\text { (fully distensibility, with } \\
\text { no or minimal tightness } \\
\text { for speculum exam) }\end{array}$ & $\begin{array}{l}\text { Fair } \\
\text { (moderate loss of distensibil- } \\
\text { ity, requiring modification } \\
\text { in speculum exam) }\end{array}$ & $\begin{array}{l}\text { Poor } \\
\text { (severe loss of distensibility, prohibiting speculum exam) }\end{array}$ & Not assessed \\
\hline $\begin{array}{l}\text { Elasticity } \\
\text { Residual }\end{array}$ & $\begin{array}{l}\text { Excellent } \\
\text { (fully distensibility, with } \\
\text { no or minimal tightness } \\
\text { for speculum exam) }\end{array}$ & $\begin{array}{l}\text { Fair } \\
\text { (moderate loss of distensibil- } \\
\text { ity, requiring modification } \\
\text { in speculum exam) }\end{array}$ & $\begin{array}{l}\text { Poor } \\
\text { (severe loss of distensibility, prohibiting speculum exam) }\end{array}$ & Not assessed \\
\hline $\begin{array}{l}\text { Thickness } \\
\text { Flap }\end{array}$ & $\begin{array}{l}\text { Normal } \\
\text { (no signs of atrophy) }\end{array}$ & Thin walls & Papery thin, transparent, visible blood vessels & Not assessed \\
\hline $\begin{array}{l}\text { Thickness } \\
\text { Residual }\end{array}$ & $\begin{array}{l}\text { Normal } \\
\text { (no signs of atrophy) }\end{array}$ & Thin walls & Papery thin, transparent, visible blood vessels & Not assessed \\
\hline $\begin{array}{l}\text { Epithelial } \\
\text { Integrity } \\
\text { Flap }\end{array}$ & $\begin{array}{l}\text { Normal } \\
\text { (no petechiae) }\end{array}$ & Petechiae after swabbing & Petechiae present prior to contact or bleeds w/ contact & Not assessed \\
\hline $\begin{array}{l}\text { Epithelial } \\
\text { Integrity } \\
\text { Residual }\end{array}$ & $\begin{array}{l}\text { Normal } \\
\text { (no petechiae) }\end{array}$ & Petechiae after swabbing & Petechiae present prior to contact or bleeds w/ contact & Not assessed \\
\hline $\begin{array}{l}\text { Vascularity } \\
\text { Flap }\end{array}$ & $\begin{array}{l}\text { Good } \\
\text { (pink) }\end{array}$ & $\begin{array}{l}\text { Fair } \\
\text { (pale) }\end{array}$ & $\begin{array}{l}\text { Minimal } \\
\text { (no color) }\end{array}$ & Not assessed \\
\hline $\begin{array}{l}\text { Vascularity } \\
\text { Residual }\end{array}$ & $\begin{array}{l}\text { Good } \\
\text { (pink) }\end{array}$ & $\begin{array}{l}\text { Fair } \\
\text { (pale) }\end{array}$ & $\begin{array}{l}\text { Minimal } \\
\text { (no color) }\end{array}$ & Not assessed \\
\hline Vaginal length & $\mathrm{mm}$ & & & Not assessed \\
\hline Vaginal diameter & $\mathrm{mm}$ & & & \\
\hline Vaginal Stenosis & Complete & Partial & Not present & \\
\hline Hair growth flap & Not present & Present & & \\
\hline
\end{tabular}

${ }^{a}$ Modified version of check-list developed and validated within The Female Sexual Medicine and Women's Health Program at Memorial Sloan Kettering Cancer Center 
Funding Open access funding provided by Karolinska Institute. Additional funding by The Regional Agreement on Medical Training and clinical research in Stockholm (Stockholms Läns Landsting, 20180017).

Data availability The datasets generated during the study are available from the corresponding author on reasonable request.

\section{Declarations}

\section{Conflict of interest None.}

Ethical approval Yes, by the Regional Ethical Committee in Stockholm, Sweden (Regional Ethical Vetting Board, Stockholm, Sweden, Dr 2015/1547-31/4).

Consent to participate Informed consent in full accordance with Swedish rules and approval by the Regional Ethical Committee in Stockholm, Sweden was obtained.

Open Access This article is licensed under a Creative Commons Attribution 4.0 International License, which permits use, sharing, adaptation, distribution and reproduction in any medium or format, as long as you give appropriate credit to the original author(s) and the source, provide a link to the Creative Commons licence, and indicate if changes were made. The images or other third party material in this article are included in the article's Creative Commons licence, unless indicated otherwise in a credit line to the material. If material is not included in the article's Creative Commons licence and your intended use is not permitted by statutory regulation or exceeds the permitted use, you will need to obtain permission directly from the copyright holder. To view a copy of this licence, visit http://creativecommons.org/licenses/by/4.0/.

\section{References}

1. Holman FA et al (2013) Dynamic article: vaginal and perineal reconstruction using rectus abdominis myocutaneous flap in surgery for locally advanced rectum carcinoma and locally recurrent rectum carcinoma. Dis Colon Rectum 56(2):175-185

2. Abbott DE et al (2008) The oblique rectus abdominal myocutaneous flap for complex pelvic wound reconstruction. Dis Colon Rectum 51(8):1237-1241

3. Bell SW et al (2005) Primary rectus abdominis myocutaneous flap for repair of perineal and vaginal defects after extended abdominoperineal resection. Br J Surg 92(4):482-486

4. Soper JT et al (2007) Comparison of gracilis and rectus abdominis myocutaneous flap neovaginal reconstruction performed during radical pelvic surgery: flap-specific morbidity. Int J Gynecol Cancer 17(1):298-303

5. Becker DW Jr, Massey FM, McCraw JB (1979) Musculocutaneous flaps in reconstructive pelvic surgery. Obstet Gynecol 54(2):178-183

6. Ratliff CR et al (1996) Sexual adjustment of patients undergoing gracilis myocutaneous flap vaginal reconstruction in conjunction with pelvic exenteration. Cancer 78(10):2229-2235

7. Germann $G$ et al (1998) The partial gluteus maximus musculocutaneous turnover flap. An alternative concept for simultaneous reconstruction of combined defects of the posterior perineum/sacrum and the posterior vaginal wall. Br J Plast Surg 51(8):620-623
8. Wagstaff MJ et al (2009) Perineal and posterior vaginal wall reconstruction with superior and inferior gluteal artery perforator flaps. Microsurgery 29(8):626-629

9. Judge BA, Garcia-Aguilar J, Landis GH (2000) Modification of the gluteal perforator-based flap for reconstruction of the posterior vagina. Dis Colon Rectum 43(7):1020-1022

10. Cordeiro PG, Pusic AL, Disa JJ (2002) A classification system and reconstructive algorithm for acquired vaginal defects. Plast Reconstr Surg 110(4):1058-1065

11. Horch RE et al (2014) A hundred patients with vertical rectus abdominis myocutaneous (VRAM) flap for pelvic reconstruction after total pelvic exenteration. Int J Colorectal Dis 29(7):813-823

12. Pelvex Collaborative (2018) Minimally invasive surgery techniques in pelvic exenteration: a systematic and meta-analysis review. Surg Endosc. 32(12):4707-4715

13. Kumar NA, Sasi SP, Shinde RS, Verma K, Sugoor P, Desouza A, Engineer R, Saklani A (2020) Minimally invasive surgery for pelvic exenteration in primary colorectal cancer. JSLS. 24(3):e2020.00026. https://doi.org/10.4293/JSLS.2020.00026

14. Holm $\mathrm{T}$ et al (2007) Extended abdominoperineal resection with gluteus maximus flap reconstruction of the pelvic floor for rectal cancer. Br J Surg 94(2):232-238

15. Dindo D, Demartines N, Clavien PA (2004) Classification of surgical complications: a new proposal with evaluation in a cohort of 6336 patients and results of a survey. Ann Surg 240(2):205-213

16. Gujral $S$ et al (2007) Assessing quality of life in patients with colorectal cancer: an update of the EORTC quality of life questionnaire. Eur J Cancer 43(10): 1564-1573

17. Wiegel M, Meston C, Rosen R (2005) The female sexual function index (FSFI): cross-validation and development of clinical cutoff scores. J Sex Marital Ther 31(1):1-20

18. Baser RE, Li Y, Carter J (2012) Psychometric validation of the female sexual function index (FSFI) in cancer survivors. Cancer 118(18):4606-4618

19. Carter J et al (2017) Vaginal and sexual health treatment strategies within a female sexual medicine program for cancer patients and survivors. J Cancer Surviv 11(2):274-283

20. Spasojevic M et al (2018) Vertical rectus abdominis musculocutaneous flap repair improves perineal wound healing after abdominoperineal resection for irradiated locally advanced rectal cancer. Ann Surg Oncol 25(5):1357-1365

21. Butler CE, Gündeslioglu AO, Rodriguez-Bigas MA (2008) Outcomes of immediate vertical rectus abdominis myocutaneous flap reconstruction for irradiated abdominoperineal resection defects. J Am Coll Surg 206(4):694-703

22. Sunesen KG et al (2009) Perineal healing and survival after anal cancer salvage surgery: 10-year experience with primary perineal reconstruction using the vertical rectus abdominis myocutaneous (VRAM) flap. Ann Surg Oncol 16(1):68-77

23. Nilsson PJ (2006) Omentoplasty in abdominoperineal resection: a review of the literature using a systematic approach. Dis Colon Rectum 49(9):1354-1361

24. Witte DYS et al (2021) Flap reconstruction of perineal defects after pelvic exenteration: a systematic description of four choices of surgical reconstruction methods. Plast Reconstr Surg 147(6):1420-1435

25. Scholefield JH, Nugent KP (2011) Anal cancer. Position statement of the association of coloproctology of Great Britain and Ireland introduction. Colorectal Dis 13(Suppl 1):1-2

26. McArdle A et al (2012) Vaginal reconstruction following radical surgery for colorectal malignancies: a systematic review of the literature. Ann Surg Oncol 19(12):3933-3942

27. Love US et al (2013) Sexual dysfunction after colpectomy and vaginal reconstruction with a vertical rectus abdominis myocutaneous flap. Dis Colon Rectum 56(2):186-190 
28. Rosen $\mathrm{R}$ et al (2000) The female sexual function index (FSFI): a multidimensional self-report instrument for the assessment of female sexual function. J Sex Marital Ther 26(2):191-208

29. Meston CM et al (2020) Scoring and interpretation of the FSFI: what can be learned from 20 years of use? J Sex Med 17(1):17-25

30. Thyo A, Emmertsen KJ, Laurberg S (2018) The rectal cancer female sexuality score: development and validation of a scoring system for female sexual function after rectal cancer surgery. Dis Colon Rectum 61(6):656-666

Publisher's Note Springer Nature remains neutral with regard to jurisdictional claims in published maps and institutional affiliations. 